\section{Commentary: Aortic valvuloplasty au naturel, where longevity is not just skin deep}

\author{
Aaron Eckhauser, MD, MS
}

In this month's edition of the Journal, Wallace and colleagues $^{1}$ explore the benefits of performing an aortic valvuloplasty in children without needing to use a patch. Spanning 36 years, this institution, which predominantly pursues surgical versus catheter-based intervention for aortic valve disease, performed aortic valvuloplasty on 102 children without the use of patch augmentation (102 of a total of 352 undergoing valvuloplasty). In this cohort, there were no early mortalities and the freedom from valve reintervention was $84 \%, 57 \%$, and $35 \%$ at 5,10 , and 15 years. The freedom from valve replacement was $93 \%$, $75 \%$, and $58 \%$ at 5,10 , and 15 years. When the authors controlled for age, neonates had a significantly lower freedom from reoperation and replacement compared with infants and older children. Patients requiring valve repair for aortic insufficiency had greater freedom from reoperation and replacement compared with those with aortic stenosis. Despite pathophysiology and quality of repair, the median age at replacement was consistently 7 to 9 years.

The significance of this paper is how it forces us to think about the long game when treating these patients. Many congenital cardiac programs lean toward a less-invasive, catheter-based approach to treat congenital aortic valve disease, and patients with either suboptimal results or inadequate anatomy veer down the surgical pathway. It is probably safe to state that both result in good short- and long-term results with minimal comorbidity and that perhaps a surgical valvuloplasty can extend the time between reintervention or replacement. ${ }^{2}$ The authors alluded

\footnotetext{
From Pediatric Cardiothoracic Surgery, Division of Cardiothoracic Surgery, Department of Surgery, University of Utah, Salt Lake City, Utah.

Disclosures: The author reported no conflicts of interest.

The Journal policy requires editors and reviewers to disclose conflicts of interest and to decline handling or reviewing manuscripts for which they may have a conflict of interest. The editors and reviewers of this article have no conflicts of interest.

Received for publication Dec 15, 2020; revisions received Dec 15, 2020; accepted for publication Dec 16, 2020; available ahead of print Dec 25, 2020.

Address for reprints: Aaron Eckhauser, MD, MS, 100 N Mario Capecchi Dr, Suite 2200, Salt Lake City, UT 84113 (E-mail: Aaron.eckhauser@hsc.utah.edu).

J Thorac Cardiovasc Surg 2021;162:1190

$0022-5223 / \$ 36.00$

Copyright (c) 2020 by The American Association for Thoracic Surgery

https://doi.org/10.1016/j.jtcvs.2020.12.077
}

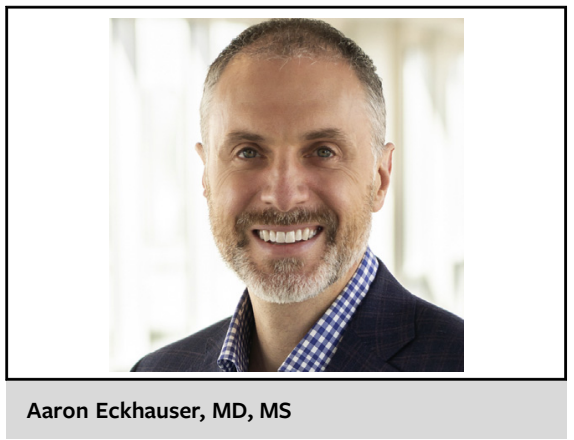

CENTRAL MESSAGE

Aortic valvuloplasty without using a patch, preferentially beyond the neonatal period, is a successful strategy to delay aortic valve reintervention or replacement until later in child- or adulthood.

to an interesting point that, in their experience, an initial surgical approach may provide better valve substrate for subsequent re-repair compared with initial catheter-based approaches. In their patients who were able to be rerepaired (23), the freedom from aortic valve replacement was $73 \%, 57 \%$, and $47 \%$ at 5,10 , and 15 years from the time of re-repair and was performed at a median of 11 years.

Reading and reflecting on this interesting experience, the one concept of which I remain convinced of is that neither catheter-based nor surgically based approaches are uniformly superior, and collaborative approaches will continue to prevail. The impetus remains on us to generate shared surgical and medical baselines; to determine what anatomic features of the congenitally malformed aortic valve, using advanced imaging and experiences such as these, are particularly suited to one approach or the other; and to be able to set reasonable short- and long-term expectations for patients and providers. This excellent paper certainly provides much insight into what can be achieved when a valvuloplasty can be accomplished with native tissue alone.

\section{References}

1. Wallace FRO, Buratto E, Naimo PS, Brink J, d'Ukekem Y, Brizard C, et al. Aortic valve repair in children without use of a patch. J Thorac Cardiovasc Surg. 2021; 162:1179-89.e3.

2. Atik SU, Eroglu AG, Cinar B, Bakar MT, Saltik IL. Comparison of balloon dilatation and surgical valvuloplasty in non-critical congenital aortic valvular stenosis at long-term follow-up. Pediatr Cardiol. 2018;39:1554-60. 